\title{
ABSTRACTS AND NOTICES FROM THE SCIENTIFIC AND TECHNICAL PRESS
}

\author{
No, 9, August, 1929 \\ Issued by the Directorates of Scientific Research and Technical Development \\ (Prepared by R.T.P.)
}

\section{Aircraft Engines, Fuels and Lubricants}

\section{Fuels, Dopes and Detonation}

Theory of Cracking Petroleum. (H. A. Wilson, F.R.S., Proc. Roy. Soc., A., Vol. I 24 , No. $793,2 / 5 / 29$, pp. 16-45.) (8.512/10425 U.S.A.)

Following two previous papers (Vol. A., I 16, p. 50I, Vol. A., I20, p. 247). Algebraic formulæ are developed for the percentage distillate, based on molecular theory. Numerical tables are given of the percentage of liquid, petrol, gas and unsaturated compounds under pressures ranging from 7.5 atmospheres to 60 atmospheres, and temperatures from $75^{\circ} \mathrm{F}$. to $1400^{\circ} \mathrm{F}$.

The variation of the percentages with temperature is also exhibited graphically, showing a maximum of 60 per cent. gasolene at $120^{\circ}$.

It is pointed out that a single distillation does not determine the maximum yield, as some of the heavier distillates may be subjected to cracking in turn.

Gum in Gasoline. (Automotive Industries, 23/3/29, p. 487.) (8.512/10426
U.S.A.)

Fuels. made by the liquid phase cracking process do not cause gum trouble in the petrol engine. If it is desired to make better anti-knock fuels, vapour phase cracking will probably be employed, and unless special precautions are taken these fuels may give trouble from valves sticking.

Knock Ratings of Pure Hydrocarbons. (A. W. Nash and D. A. Howes, Nature, 1929, $123,526-527$.$) (8.514/10427 England.)$

Accurate knock rating requires careful standardisation of methods. An acid refined unsaturated spirit has a lower anti-knock value than the original, since the ollefines only polymerise incompletely. Both for the ollefines and also possibly for the aromatics ease of oxidation appears to be connected with anti-knock value.

Knock Ratings of Pure Hydrocarbons. (S. F. Birch and R. Stansfield, Nature, 1929, 123, 490-49r.) (8.514/10428 England.)

Polymerisation generally reduces the anti-knock value of the fuel. The behaviour of cyclo-hexane depends on the history of the sample. Hydro-carbons which possess conjugated double links have high anti-knock qualities. An increase in the length of a chain generally reduces the anti-knock properties. The reverse is the case for side chains attached to a benzene ring.

The Speed of an Explosive Wave. (P. Laffitte and P. Dumanois, Ann. Office Nat. Comb. Liquides 3, I21-2, 1928.) (8.514/10429 France.)

Experiments show that the speed of propagation of a detonating wave in mixtures of hydrogen and oxygen or methane and oxygen is not affected by the addition of .I per cent. of tetraethyl lead. 
X-Ray Quantitative Analysis of Tetraethyl Lead in Gasoline. (R. H. Aborn and R. H. Brown, Ind. Eng. Chem. Analy., Ed. I, 26/7, 1929.) (8.514/10430 U.S.A.)

By comparing the sample with the X-ray photograph of standard solutions it is claimed that the lead tetraethyl content can be estimated to . I per cent.

Effect of Anti-Knock Materials on the Speed of Initial Uniform Movement of the Flame in Hydrocarbon Air Mixtures. (Yuzaburo Nagai, Tokyo Imp. Univ. Proc. Imp Acad. 4, 525-8, 1928. Chemica! Abstracts, 20/3/29, Vol. 23, No. 6, p. I 500.) (8.5 I $4 / 1043$ I Japan.)

The effect of $\mathrm{SeEt}_{2}, \mathrm{SnMe}_{4}$ and $\mathrm{PbMe}_{4}$ on the speed of initial uniform movement of the flame in a mixture of air and hydrocarbon vapour has been studied. The hydrocarbon consisted of a mixture of about 43 per cent. dimethylcyclopentane and 57 per cent. isoheptane. The speeds of the initial uniform movement of the flame are distinctly lowered by the addition of the anti-knock materials, the speed concentration (of hydrocarbon) curve being lowered more and more with the increase in concentration of the anti-knock materials. When the concentration of $\mathrm{SnMe}_{4}$ or $\mathrm{PbMe}_{4}$ reaches I per cent., the curve is not lowered by further addition of these compounds, the concentration of $\mathrm{SeEt}_{2}$ to produce the same result is about 2 per cent.

Standardisation of Conditions for Measuring the Detonation Characteristics of Motor Fuels. (R. Stansfield and F. B. Thole, Industrial and Engineering Chemistry, Analytical Edition, Vol. I, No. 2, I5/4/29.) (8.514/10432 U.S.A.)

Three designs of engine are described with entirely different combustion chamber shapes and valve arrangements. Tests show that substantially equal results for anti-knock can be obtained from any of the engines if comparisons are made in terms of equivalent blends of standard spirits and provided that test conditions are suitably controlled.

The effect of each controllable variable is examined, the most important. being the air fuel ratio and, in the case of tests with the bouncing-pin indicator, the compression ratio at which comparisons are made.

The air fuel ratio must be adjusted to give maximum pinking and, for bouncing-pin tests, the sample must be used undoped and the compression ratio adjusted to give the necessary evolution of gas in the voltmeter.

Experimental errors of different methods of test have been determined and vary from \pm 2 to \pm 0.25 per cent. of benzene in heptane, the bouncing-pin method giving the closest agreement between repeat tests.

$\mathrm{N}$-heptane and pure benzene are suggested as suitable for standard reference blends, but there is need for a cheaper and more easily obtainable low-value spirit than heptane.

Combustion Control by Cylinder Head Design. (Robert N. Janeway, S.A.E. Journal, May, I929, page 498.) (8.514/10433 U.S.A.)

Since detonation depends primarily upon the temperature attained by the residual unburned gas, it can be controlled by combustion chamber design which intensifies the heat transfer from the unburned gas to the walls.

The shock tendency, which originates in the pressure time characteristic of combustion, can be controlled only by deliberate incorporation of the desirable anti-shock characteristic in the chamber design by a method of calculation which is explained in detail. To obtain smoothness without loss of power the volume of charge must be so distributed with respect to the firing position as to obtain nearly as possible uniform acceleration in the rate of pressure rise up to the maximum rate, without excessive increase in the explosion time. 
Heat Effects on Aluminium Alloy Pistons. (Ralph N. Du Bois, Automotive Industries, I9/r/29, pp. 90-94.) (I0.23/10434 U.S.A.)

The pistons were fitted from the inside with I I thermo-couples I/I6th inch below the outer surface. The combined wires from the couples were led out through a steel tube attached to the skirt and through the crankcase, along an aluminium lever to a fixed point. The measurennents obtained were checked by fitting the piston with a number of fusible alloy plugs. The effects of spark setting, speed and wall temperature were investigated. It was found that the increase of piston temperature with spark advance was linear even at spark settings beyond optimum advance. An examination of all the piston heads showed that there was a cool zone apparently swept by the incoming charge extending partly around the circumference and causing the exhaust side of the piston head to run considerably cooler than the intake side. The engine was a four-cylinder motor car type, operating at speeds up to 2,000 r.p.m. and developing about 30 h.p.

\section{Lubricants and Lubrication}

The Physical Principles of Lubrication, in Particular for the Explosion Engine. (S. Kyropoulos, Z. Tech. Physik 10, 2/18, 1929.) (8.4/10435 Germany.)

Slight additions of castor oil to mineral oil produce a considerable saving of oil consumption of internal combustion engines. This is attributed mainly to decrease in the vapour pressure of the mineral oil. Oils of high viscosity produce higher running temperatures with an increase in oil combustion. The best results are obtained by using oil of medium viscosity and adding small quantities of stearic acid or castor oil.

Corrugations in Bearings and the Deterioration of Oil in Oil Engines. (E. Falz, Motorwagen, Vol. XXXII., Part ro, roth April, 1929, pp. 205-2 I2.) (8.4/10436 Germany.)

A descriptive account is given of the conditions under which diminution in the viscosity of the oil may render the depth of the lubricating layer less than the size of small solid particles in suspension, whereupon the latter are lodged firmly in the surface of the bearing.

Photographs of fine mesh air and oil filters are reproduced, and a microphotograph of a special bearing metal, rich in graphite, for which tests indicate specially good results.

Lubricating Oil Specifications said to Lack Value for Car Users and Designers. (C. Edward Packer, Automotive Industries, 13/4/29, pp. 586-587.) (8.41/10437 U.S.A.)

Buying oil by specification is useless, since no specification at the present moment meets conditions occurring in practice. Such factors as gravity, pour point and flash point may be regarded as a makeshift to compensate for a large factor of ignorance.

The carbon residue test was originally developed for comparison of the carbon-forming properties of lubricating oils for internal combustion engines. It is frequently claimed that the quantity of carbon deposited in cylinders and on pistons is proportional to the carbon residue of the oil. Under ideal conditions this is probably true, but with average operating conditions, other factors such as the viscosity of the oil, the mechanical condition of the engine and the conditions of carburation of the fuel, may dominate in controlling carbon deposition.

The organic acids normally present in lubricating oil are not corrosive and have no directly harmful effects, the general quality of a lubricating oil cannot be evaluated in terms of its neutralisation number. 
Determination of Oxidisability of Transformer and Turbine Oils. (N. I. Tschernoshukov, Izvestia Teplotech. Inst., Moscow, 1928, 10, 13-18.) (8:41/10438 Russia.)

Three rapid methods for measuring the asphalt and hydroxidi-acid content of oils are described. The results obtained by the Butkov test show that this method is simple and rapid and of geaeral application for control purposes.

Recovery, of Lubricating Oil. (Der Motorwagen, No. 12, April 3oth, 1929.) (8.44/10439 Germany.)

After filtering off carbon and other particles, the old crankcase oil is regenerated by passing it through a layer of aluminium-magnesium-hydrosilicate. This material has the property of absorbing acid oxidation products, metal soaps and polymerisation products. It also polymerises unstable unsaturated compounds and absorbs them subsequently. The material is known under the trade name of "Floridin," and regenerators employing it have been built by Messrs. Bensmann for a number of yaars with success.

Properties and Analysis of Used Crankcase Oils. (D. G. Pidgeon and H. R.

Tester, J. Inst. Petroleum Tech., I929, 15, 9I-99.) (8.44/10440 U.S.A.)

Distillates obtained by passing. superheated steam into samples of used oils show that they consist mainly of heavy fractions of motor fuel together with cracked products of the lubricating oil. For :ny particular engine the percentage dilutior reaches an approximately constant and characteristic value. Under certain conditions the dilution is such that a heavy grade oil is necessary at the start, in order that a safe viscosity may be reached. The amount of oxidation produced is not a function of the percentage dilution.

\section{Thermodynamics}

Carbon Monoxide from Automobiles Using Ethyl Gas. (W. P. Yant and L. B. Berger, Bur. Mines Repts. of Investigations, No. 2908, 8 pp., 1929.) (8.57/1044I U.S.A.)

Tests showed no difference in the $\mathrm{CO}$ content of exhaust gas when detonation was present or inaudible. When running on a retarded spark there was some evidence of the $\mathrm{CO}$ content being less when ethyl gas was used than for straight petrol.

Flame Speeds and Their Calculation. (W. Payman and R. V. Wheeler, Fuel, Vol. VIII., No, 5, May, 1929, p. 204.) (8.57/10442 U.S.A.)

A series of experiments has been carried out in Prof. H. B. Dixon's laboratory with a number of mixtures of hydrogen, oxygen, and nitrogen of different compositions, using the original apparatus in which his experiments were carried out. These experiments have shown that the law of speeds holds for the rate of detonation in these mixtures. The law of speeds applies to the detonation wave in these mixtures for a similar, but not identical reason to that which makes it applicable to the uniform movement of flame, and only for mixtures containing sufficient oxygen for complete combustion.

The Activity of Various Catalysts in Promoting the Oxidation of Methane by Means of Oxygen. (J. R. Campbell, Chemistry and Industry, 3/5/29, Vol. 48, No. i8, p. 93.) (8.57/10443 U.S.A.)

The presence of catalysts does not affect the scheme of the course of oxidation proposed by Bone. The various stages of oxidation succeed each other very rapidly and intermediate oxidation products are not easily isolated in quantity. Of the catalysts studied (silver oxide, copper oxide, vanadium oxide, platinised asbestos, platinum black and vanadium black), platinum black proved the most effective and copper oxide the least effective. 
Kinetics of the Combustion of Carbon Monoxide. (W. Kinkelstein and W. Maschowetz, Zeit. f. Phys. Chem. 138, Abt. A.6, pp. 369-378, Dec., 1928.) (8.57/10444 Germany.)

The combustion of carbon monoxide contained in glass vessels is affected by the nature of the surface of the vessel. Fresh clean surfaces act catalytically in promoting combustion. The carbon monoxide molecules coming in immediate contact with activated oxygen molecules at the surface a vigorous reaction ensues at first. The carbon dioxide produced becomes absorbed by the glass layer and thus poisons its activation. The speed of reaction thus diminishes, but can be restored by treating the surface with concentrated nitric acid.

Ignition Combustion Phenomena in Diesel Engines. (Z.F.M.; 10/9/27, p. 1287, by F. Sass.) (8.57/10445 Germany.)

Evidences were found that neither gasification nor vaporisation of the injected fuel occurs before ignition; also that the hydrogen coefficient has no significance. However, the knowledge of the ignition point and of the "time lag" is important. "After ignition, the combustion proceeds in a series of reactions, the last of which at least is now known. The paper has been translated in full by the National Advisory Committee for Aeronautics as Technical Memorandum No. 482 .

Contribution to the Study of Flame Propagation in Gaseous Mixtures. (M. R. Duchene, Service Technique et Industriel de l'Aeronautique, Bulletin Technique, No. 54, December, 1928.) (8.57/10446 France.)

The fuel mixtures were compressed adiabatically by means of a piston and then fired by means of an electric spark. The resulting flame was photographed on a rotating film. Experiments were carried out with benzene, cyclo-hexane, cyclo-hexene and hexane. It was shown that the chemical reaction in the mixture is not completed by the passage of the flame but by adiabatic compression produced by the reflection of pressure waves. 'The chemical reaction proceeds in stages and the presence of tetra-ethyl lead dope renders sudden completion of the reaction by a pressure wave more difficult. The article contains original flame photographs.

The Gaseous Explosive Reaction. A Study of the Kinetics of Composite Fuels. (By F. W. Stevens, Report No. 3०5, National Advisory Committee for Aeronautics.) (8.57/10447 U.S.A.)

In a series of studies of the kinetics of gascous explosives reactions the fuel under observation, instead of being a simple gas, is a known mixture of simple gases. In the practical application of the gaseous explosive reaction as a source of power in the gas engine, the fuels employed are composite, with characteristics due to the components and hence somewhat complex. The investigation of the thermodynamics or kinetics of the gaseous explosive reaction of the fuel is followed by a study of the reaction characteristics of the various known mixtures.

Studies of the Dynamics of Ignition. (O. Klusener, V.D.I., 3/1 1/28, p. 1580 .) (8.57/10448 Germany.)

Simultaneous records of the flame position and pressure were obtained, using heptane air mixtures. The effectiveness of the shape of explosive vessel, position of igniter, and turbulence were examined. The author is of the opinion that ignition by pressure waves is quite general and occurs whether audible detonation is present or not. Only in this way can the high rates of ignition observed in engines be accounted for, turbulence alone being insufficient. 


\section{Carburation}

Producing a Combustible Charge for Use in Internal Combustion Engines. (D. Balachowsky, P. Caire and M. Levy (B.P. 302, $7^{17}, 28 / 3 / 28$, Fr. $21 / 12 / 27$ ), Chemistry and Industry, B., Vol. 48, No. r7, 26/4/29.) (8.53/10449 U.S.A.)

The combustible charges are obtained by passing a mixture of air and petrol over a catalyst formed of one of the metals known to decompose hydrocarbons. The catalyst is heated by the exhaust of the engine, careful tension control being essential for the satisfactory working.

Combustion in Motors in which the Fuel and Air are Mixed before admitting to the Cylinder. (A. Grebel, Chimie et Industrie $20,8 \mathrm{I} 3-8,1928$.) (8.53/10450 France.)

The study of combustion in engine cylinders shows that with the normal type of carburettor the limit of possible efficiency is reached. In the Catalex carburettor the fuel and air are mixed in the presence of a catalyser before admission to the engine. This should lead to a further improvement in efficiency.

Investigation into the Atomisation Produced by a Jet Carburettor. (J. Souter, V.D.I., 3/11/28, p. I572.) (8.53/1045 I Germany.)

The size of the particles emitted by the carburettor are measured by a photometer. In the case of paraffin the size of the fuel particles varied from 3 to $33 \times 10^{-3} \mathrm{mms}$.

\section{Heavy Oil Engines}

Diesel Engines for High Speeds. (A. Reinsch, V.D.I. 72, pp. I37-1375, Sept., 29th, 1928.) (8.59/10452 Germany.)

Representative types of German Diesel engines operating at speeds above I,, 00 r.p.m. are described. The types include both air injection, solid injection, two-stage ignition and an air storage method.

Research on the Diesel Engine, Pre-Combustion Chamber Engine. (K. Neumann, V.D.I. 72, pp. I 241-1248, Sept. 8th, 1928.) (8.59/10453 Germany.)

From a mathematicai analysis of experimental results it is concluded that the combustion in the pre-combustion chamber occurs with considerable excess of air. The explosion in the chamber projects the unburned fuel into the main part of the cylinder. The temperature of the chamber and connecting passage are of the same order as the wall temperature of normal internal combustion engines. The pre-combustion type is considered to be especially adapted for the combustion of heavy oils as it is less sensitive to the possible stoppage of fuel orifices.

\section{Packard Diesel Flown to Virginia. (Aviation, 25/5/29, p. 1803.) (8.59/10454 U.S.A.)}

The Packard Diesel is a 5 -cylinder air-cooled 1adial with an estimated weight of 3 lbs. per h.p. A demonstration of the engine was given at the Fourth Annual Conference of the National Advisory Committee for Aeronautics. A cabin monoplane, fitted with the engine, flew non-stop from Detroit to Langley Field, a distance of approximately 700 miles. The average speed was $100 \mathrm{~m}$.p.h., and from the weight of fue! consumed it appears that the h.p. of the engine must be in the neighbourhood of 200 . 
The Acro-Bosch High Speed Diesel Engine. (Prof. R. Stribeck, V.D.I., May 28th, 1927, p. 765.) (8.59/10455 Germany.)

Experiments were carried out on an engine $120 \mathrm{mms}$. bore, $180 \mathrm{mms}$. stroke, running at speeds between 400 and 800 r.p.m. Using the method of Paterson (Forschungs-arbeiten No. I43) the temperature was measured in the combustion space of the engine under running conditions. In the Acro engine a special shaped receptacle is placed in the piston crown into which fuel is injected, at the end of the compression stroke. The whole of the clearance volume is practically in this space and the experiments show that a flame persists at the mouth of the receptacle and is fed by clean air from the exterior of the receptacle, the burnt products forming above the piston on the downward stroke. The speed of the air feeding the flame varies directly as the speed of operation, and this accounts for a constant fuel consumption per unit power irrespective of speed over the range examined. The experiments also demonstrate that the engine works on a different principle from the twostage ignition engine and there can be thus no question of patent infringement.

\section{The Dorner Fingine: (V.D.I., 28/5/27, p. 781.) (8.591/10456 Germany.)}

This engine has been taken up by the American firm of Packard. The following test figures obtained by Prof. Noyman refer to an earlier model. The engine has a bore and stroke of 95 and $160 \mathrm{mms}$. respectively. Normal operation is $I, 000$ r.p.m. The maximum b.e.p. obtained was Ioo pounds per sq. in. with a fuel consumption of 0.46 pounds per b.h.p. hour. Plain solid injection is effected by a jug pump and a spring loaded fuel valve nozzle. The fuel pump is accurately controlled by altering the effective stroke; ports cut in the pump system are employed as inlet valves.

Combustion and its Difficulties in Marine Oil Engines. (K. O. Keller, Transactions of the North East Coast Institution of Engineers and Shipbuilders, Vol. XLV., Pt. 4, March, 1929, p. 185.). (8.591/10457 England.)

Various points are enumerated affecting combustion in internal combustion engines of the air-and airless-injection types, modes of injection, shapes of combustion spaces, methods of scavenging, with data on the velocity of the rotating air as measured on Doxford engines.

Compression Ignition Engines-their Application for Aeronautical Purposes. (M. Poincare, La Technique Aeronautique, No. 86, 15/12/28.) (8.591/10458 France.)

This French review deals mainly with the well-known German injection engines, built by Bosch, Deutz, Benz, Koerting, M.A.N. and Junkers. Amongst French engines the Tartaris, Jalbert and Rochefort are described. The Jalbert uses a carburettor for metering out the fuel. The Rochefort depends on air turbulence for injection, ignition being by means of a spark. The lead held by German designs is emphasised throughout.

\section{Two-Stroke Engines}

Improvements in Two-Stroke. (Motor, May, I929, p. 58.) (8.871/10459 Germany.)

In the Rinne two-stroke engine the baffle plate on top of the piston is arranged to produce turbulence of the compressed charge just prior to firing. This is obtained by so shaping the combustion head that the baffle plate traps part of the charge and compresses it at a greater rate than the remainder. 
Crankcase Scavenging for Two-Stroke Engine. (Dr. Ing. H. List, V.D.I.,
I6/2/29, p. 225.) (8.871/10460 Germany.)

The air consumption of two-stroke engines using crankcase scavenging is calculated and the result shown graphically. A method is described for determining the volumetric efficiency of such cylinders experimentally. The mean effective pressure and most favourable length of inlet ports is determined.

The Development of the Two-Stroke Engine. (Technical Notices of the Italian Air Ministry, No. I2, December, i928, page ro.) (8.871/1046r Italy.)

This is a critical review of a series of articles which have appeared in "La Technique Automobile et Aérienne," Nos. I 40, I4I, I42. The importance of supercharging and scavenging is pointed out. The Fiat and Ferrara engines are described, the latter is of the U-type combustion chamber type with cylinder axes inclined. Details of oil-cooling for pistons are given.

\section{Engines, Design, Accessories, Etc.}

New Compensating Piston Supported at Top by Ring and Invar Bar. (Automotive Industries, $9 / 3 / 29$, p. 418 .) (8.2/10462 U.S.A.)

The design differs from conventional pistons chiefly in two respects. At the open end, the piston diameter is slightly larger in the plane of connecting rod than in the plane through the piston pin axis. At the head end, the piston bears on the cylinder wall through a cast iron ring, which is rigidly supported by a flat invar steel insert, held central with respect to the piston by being anchored at the centre of the head, and passing through slots milled at the bottom of the ring groove.

Unsymmetrical Cranlshafts for V-Fngines Producing Better Balance.

Schroen, Der Motorwagen, 30/5/29, p. 311.) (8.22/10463 Germany.)

(H.

The unsymmetrical crankshaft has the fundamental property that no forces of the first and second order or noments of the second order exist. Moments of the first order, either due to rotating or reciprocating masses can be balanced provided the angle of the $\mathrm{V}$ is $90^{\circ}$.

Torsional Vibrations of Crankshaft. (E. A. Wedemeyer, Zeitschrift fur Flugtechnik und Motorluftsschiffahrt, 28th March, I929, Part 6, page 145.) (8.22/10464 Germany.)

A method of calculating critical periods is developed which is considered to be more rapid and certain than existing methods. A detailed calculation of a six-throw crankshaft exhibits a concise solution of the differential equation by means of a series as first proposed by Brauchitsch.

An uncertainty is introduced by the magnitude of the damping coefficient which is estimated as 0.005 kilogrammes per sq. $\mathrm{cm}$. of piston area. If resonance cannot be clearly avoided vibration dampers should be fitted.

Balance of Internal Combustion Engines. (W. Kerr, Inst. Eng. and Shipbuilders, Trans. 7r, pp. 693-749, Disc. 749-768, Aug., I928.) (8.221/10465 England.)

The forces are divided into frame and shaft forces and the angle acceleration of the connecting rod is allowed for by the introduction of a special couple. The motion is expressed in terms of a Fourier series, the coefficients being determined arithmetically, 
Contribution to the Stressing of Power Units for Aeroplanes. (O. Steigenberger, Z.F.M., March 14th, 1929, p. 113.) (8.24/10466 Germany.)

The forces on the crank pin and crankshaft for various types of engines are calculated and the results shown graphically. Three special cases are considered: ( 1 ) The engine running light; (2) the engine running on the normal power; (3) the aeroplane nose-diving with the engine switched off. The case of a nine-cylinder radial engine and a 12 -cylinder $V$ engine is studied in great detail.

Investigation into the Mechanics of the Fairchild-Caminez Engine. (Dipl. Ing. Zimmermann, Der Motorwagen, May 2oth, 1929, page 300.) (8.89/10467 Germany.)

The Fairchild engine with a bore of II $4 \mathrm{~mm}$. and a stroke of $143 \mathrm{~mm}$. develops $\mathrm{r} 35$ horse-power at $\mathrm{r}, 05^{\circ}$ r.p.m. In the article the forces acting on the roller as well as the side pressures on the piston have been calculated and compared with those occurring in a normal five-cylinder engine of equal output. The conclusion reached is that the cam drive embodied in the Fairchild engine is not as efficient as the normal method of operation. Whether the reduction in airscrew speed inherent in the Fairchild design outweighs this disadvantage is problematic.

Long Intake Pipes may Increase Engine Output. (Automotive Industries, I $3 / 4 / 29$, pp. $5^{\left.82-5^{8} 4 .\right)}\left(8.57^{1 / 10468 ~ I t a l y .)}\right.$

A report on an investigation into the effect of long intake pipes on engine output by the Italian writer, A. Capetti, has been translated by the National Advisory Committee for Aeronautics. The author points out that the intake pipe is traversed by a pulsating current of combustible mixture and that the phenomena of flow are quite similar to those in alternating electric circuits. Considerable supercharging may be effected by suitable tuning. The effect of a capacity in parallel to the velocity of airflow in the inlet pipe is especially marked. Capacity is placed either at the beginning or end of the inlet pipe, but gives generally little result.

Cowling of Air-Cooled Radials. (Notiziario Technico di Aeronautica, No. 3, March, 1929, p. 37.) (8.38/10469 Italy.)

In connection with the cowling described by N.A.C.A., the cowling designed by Piero Magni and fitted to a sports machine, Vittoria $19^{2} 4$, is described. In the Italian design, circulation through the cowling is increased by fitting a pair of subsidiary propellers inside the cowling. The spinner attached to the main propeller has the central hole through which air enters the cowling. The exit of the air through a circular flange, placed well to the rear of the engine, is in the manner of the American design.

N.A.C.A. Cowling Experiments Interest S.A.E. at Detroit. (Athel F. Denham, Automotive Industries, 20/5/29, pp. 627-628.) (8.38/10470 U.S.A.)

In attempting to apply the N.A.C.A. cowling to multi-engined aeroplanes disappointing results were obtained at first. These were traced to interference effects between the cowling and the lower wing surface. It is evident that certain precautions have to be taken, among these:-

I. The cowling and fuselage behind it must form a perfect streamline shape.

2. Frontal openings must be sufficient to admit enough cooling air for all cylinders.

3. Baffling or some form of directional air control inside the cowling must be provided to see that no air is wasted. Thus, the J-5 cowling had plates for the magnetos and deflectors near the rocker arm boxes, which required no cooling. 
500 h.p. Panhard Sleeve Valve Engine. (L'Aerophile, March, 1929, p. 81.)

(8. $5^{61 / 1047 \text { I France.) }}$

The engine is a 12 -cylinder $\mathrm{V}$ with a bore and stroke of 140 and $\mathrm{I}$ 70 $\mathrm{mms}$. Its normal speed is $I, 700$ r.p.m. and the weight approximately $I, 000$ pounds. Two steel sleeves are used per cylinder.

(contrifugal Oil Cleaner. Contribution towards the Problem of Cleaning Engine Oil. (W. Schwerdtfeger, Der Motorwagen, 20/4/29, p. 234.) (8 $44^{i}$ i 0472 Germany.)

A centrifugal type of oil cleaner is described which is worked by the oil flow direct without the interposition of gearing. The pressure drop is of the order of one atmosphere, microscopic examination of the oil has revealed the absence of all particles in excess of $1 / 500$ th $\mathrm{mm}$. diameter.

Supercharging of I.C. Engines. (C. Waseige, La Technique Aéronautique, No. 89, I.5/3/29, p. 42-62.) (8.62/1047.3 France.)

The Rateau centrifugal single-stage fan as adopted by Farman runs at 20,000 r.p.m., a centrifugally loaded friction clutch being interposed between the engine and the step-up gears. When out of action the blower is driven at engine speed and absorbs under these conditions about five horse-power. The fan thus accelerates not from rest but from 2,000 r.p.m., the normal engine, speed. If at rest, when not in use, it would throttle the engine intake excessively. If declutched, but rotated by the air taken, it would absorb about 35 horse-power. If driven at full speed and throttled at intake the power consumption amounts to over 80 horse-power. The Farman solution of the problem thus amounts to providing a two-speed gear. For efficient working a third speed should be provided. The power consumption at 5,000 metres is 80 h.p. From the quantity of air delivered and the temperature rise, the Farman blower has an adiabatic compression efficiency of approximately 50 per cent. The weight of the installation is given as Io7 lbs.

Automatic Ignition Advance on Scintilla Magneto. (Der Motorwagen, No. I 2, April 3oth, 1929.) (8.91/10474 Switzerland.)

A centrifugal device is incorporated in the inductor of the magneto and causes an advance of the spark burning with speed. The dimensions of the magneto are not affected by the device, which has now given satisfactory service for several years. 'The makers are the well-known Swiss firm, Scintilla, of Solcure, whose magneto has practically become standard in U.S.A.

Engine Cooling Fluid Developed by the United States Army. (Aviation, 30/3/20, p. 965.$) \quad(8.33$ r $/ 10475$ U.S.A.)

Tests carried out with a fluid other than water as the cooling medium in engine radiators has resulted in a saving in weight of over $\mathrm{I} 20 \mathrm{lbs}$. Instead of the usual 18 gallons of water only $4 \frac{1}{2}$ gallons of the chemical are required, this alone resulting in a saving in weight of over $80 \mathrm{lbs}$. The additional saving ir: weight is due to the possibility of using a smaller radiator. The fluid has a boiling point of $200^{\circ} \mathrm{C}$. and further details are promised by the Secretary for War of Aviation.

High Temperature Cooling Agent Found in Ethylene-Glycol. (Edmund B. Neil, Automotive Industries, April I $3^{\text {th, }}$ 1929, pp. 597.) (8.331/10476 U.S.A.)

Experiments have been carried out recently by the American Government with a new cooling agent, the composition of which at first was not divulged. It is now known that ethylene-glycol was used, a substance which has been known 
as an anti-freeze for several years. The boiling point of this substance is approximately $200^{\circ} \mathrm{C}$. Its specific heat is roughly two-thirds that of water and its density I.II4. It is stated that by the use of this substance a considerable saving in the weight of the power plant can be effected. Part of this saving is due to reduction in the size of the radiator required, the remainder is due to the smaller quantity of cooling fluid necessary.

\section{AIRCRAFT DEsign}

\section{Aerodynamics and Hydrodynamics}

Aerodynamics and Hydrodynamics. Double Row of Vortices with Arbitrary Stagger. (L. Rosenhead. Proc. Camb. Phil. Soc,, Vol. XXV., Part II., 1929, pp. I $32-138) \quad.(5.32 / 10477$ England.)

The author examines, generally, the conditions of equilibrium and stability for all possible arrangements of two parallel rectilinear rows of equal and equally spaced vortices, the signs being different in the two rows.

The eliminant is formed of the four arbitrary constants in the linear differential equations obtained by assuming initial equilibrium, and it is shown that v. Karman's arrangement alone is in neutral equilibrium and that of the other possible arrangements the symmetrical one alone is in unstable equilibrium.

(The argument does not appear to be entirely consequent, but the results are no doubt correct for two-dimensional disturbances.)

Benard's Alternate Vortices in a Channel of Finite Dimensions. (H. Villat, Comptes Rendus, Vol. I88, No. 18, 29th April, 1929, pp. I129-II32. (5.32/10478 France.)

v. Karman's criterion of stability is written down and transformed to take into account the repeated reflections which divide the whole plane into a network of equal rectangular meshes. The velocity field is now expressed in zeta elliptic functions, the periods of which are given by the sides of the mesh.

The stream function is given in terms of sigma functions and the resistance of the cylinder in terms of zeta and Weirerstrassian functions, the periodicity of the stream function giving a relation of immediate practical importance.

When the walls are taken to a distance the expression for the resistance approaches a limit differing from $v$. Karman's result. This is due to the fact that the stream functions at the boundaries have now a finite difference of value. The physical explanation is that walls, even at a large distance compared with the width of the vortex street, impose the condition of equal inflow and discharge on the canalised stream, which is absent in an inciefinitely great mass of fluid.

A comparison with experiment is to foliow.

\section{Influence of the Shape of the Nose of Blade Profiles of Centrifugal Pumps on \\ Cavitation. (H. Pöter, Z.F.M., Vol. 9, Part 2, April, 1929, pp. 85-1or.) (5.33/ro479 Germany.)}

The problem is considered in its two-dimensional form. The surface of the blade at the nose is replaced by a linear distribution of sources and the effect on a velocity field calculated in the usual way. The distance from the nose of the point of maximum pressure drop is calculated for a variety of cases and exhibited in a table.

The drop of pressure is also exhibited as a function of the curvature for blades of equal chord and thickness, but with five shapes of nose rounded off in different manners.

Conclusions are drawn as to the most suitable type of nose to avoid cavitation. 
Full-Scale Tests on a Thin Metal Propeller at Various Tip Speeds. (F. E. Weick, National Advisory Committee for Aeronautics, Report No. 3o2.) (5.421/10480 U.S.A.)

An investigation was made to determine the effect of tipi speed on the characteristics of a thin-bladed metal airscrew mounted on a VE-7 airplane with a 180 h.p. E-2 engine, and tested in the $20-f o o t$ research tunnel. The effect of tip speed on the efficiency was negligible within the range of tests, from 600 to $I, 000 \mathrm{ft}$, per sec. (about 0.5 to 0.9 of the velocity of sound in air).

Aerodynamics of Wings. (Anon. Revue Generale de L'Aeronautique, Vol. ro, I 929, p.p. I-I 1 2.) (5.31/1048I France.)

The article is a useful exposition of Joukowsky's theory of profiles, of Prandtl's exposition of the physical causes of circulation and of developments by v. Mises, Betz, Munk and others.

Some Problems Confronting Present Day Aerodynamics. (Dr. H. Blenk, V.D.I., Oct. 8th, 1928, p. I 395.) (5.3/10482 Germany.)

The requirements of safety and efficiency, unfortunately, oppose one another. Mutual wing interference in a biplane is fairly well understood. Interference between the wings and the tail plane, between the wings and the body, between the airscrew and the aircraft as a whole remain obscure. Experiments are wanted with aerofoils of various profiles at speeds exceeding the velocity of sound. Structural resonance may be due to the equality of the free period of some part with the period of the engine or of eddies thrown off. Wing flutter may be produced by the inter-action of restoring forces due to torsion and bending and disturbing fores depending on the incidence. During recent gliding experiments many examples of wing and tail flutter were studied and the various methods of eliminating them are described. A fairly extensive bibliography is given.

Results of Gliding Competitions in 1928. (W. Georgii and A. Lippich, Z.F.M., Vol. 20, P. 3, 14/2/29, pp. 57-70.) (5.322/10483 Germany.)

An analysis is given of the French gliding competition at Vauville near Cherbourg, July, I928, and of the Rhön competition August, 1928. Contour maps are given of the surrounding country and indications of the prevailing winds. The performance of the German competitors is given in considerable detail, as to times and distances flown without landing, a flight of 29 kilometres by Hierth being noteworthy.

Much more extensive analysis is given of the German competition in the Rhön valley, the contour lines, the plan of the flights, the barograms, the effects of cumulus clouds, etc., being exhibited graphically.

A second technical account by A. Lippich gives photographs and dimensioned sketches of competing gliders along with formulæ used for reductions and polar diagrams.

Displacement Resistance. (H. Lorenz, Z.F.M., Vol. 20, P. 6, 28/3/28, pp. I 4 I-I 43.$) \quad(5 \cdot 32 / 10484$ Germany. $)$

An analysis of the body resistances is attempted but it is difficult to find any new physical principle in spite of novel terminology.

The Critical Length of Aeroplane Wings. (J. Mather, Report from Aerodynamical Institute, Aachen. Z.F.M., Vol. 2o, P. 6, 28/3/29, pp. 143-145.) (5.2 I I/10485 Germany.)

Applying the usual methods of analysis for forced vibrations the author finds that there is a critical length at which vibration sets in which is related to the 
loading, the bending stiffness, the distance between the spars, and the torsion in a definite manner. Some of these relations are given graphically.

Slotted Wings. (Automotive.Industries, 20/4/29, p. 628. C. B. Harper, Bureau of Aeronautics.) (7.6/10486 U.S.A.)

The installation of a slot on any new airplane requires a great deal of "tailoring" and research in order to obtain maximum effectiveness; with high lift airfoil sections the gain of control effectiveness after the stalling point has been reached for the normal wing is not so pronounced.

In the work of the navy on this subject, a "spoiler" flap working in conjunction with the aileron control has proved rather effective. The flap is built into the upper wing side just back of the top of the camber. In operation, the rear edge of the flap swings upward and forward about the front edge, " spoiling" the air flow over the wing and assisting the aileron in dropping that wing.

Suggestions for Appuratus, etc., for Teaching Elements of Aerodynamics in Schools. (Dipl. Ing. C. Boving, Luftfahrt, No. 8, 22/4/29.) (I I.II/10487 Germany.)

A small scale wind channel of the open flow type operated with a 2 h.p. electric motor renders possible a series of fundamental experiments in aerodynamics. A simplified two component balance is described and methods are given for making model profiles of various sections.

Apparatus for Measuring Aerodynamical Velocities Round an Aeroplane. (E. Huguenard and A. Magnan, Comptes Rendus, Vol. I 88, No. 7, II/2/29, pp. 484-487.) (11.15/10.488 France.)

The apparatus consists of two Pitot tubes of the same type placed at different positions but connected to a differential monometer with a quick reading needle, recording the differences on a rotating cylinder.

The instrument has been used for exploring velocity round an aeroplane. It can also be used to determine the rotations of the airscrew which produce no effective wash for a given aeroplane speed, the null point being indicated by zero reading of the manometer needle.

In the latter measurements one Pitot or Venturi tube is placed outside the influence of the screw and the other behind it. Further details of the mounting are given.

Combined Lateral and Longitudinal Oscillations of an Aeroplane. (A. v. Baranoff and L. Hopf, L.F.F., Vol. 3, Part 2, 20/3/29, pp. 39-58.) (7.21/10489 Germany.)

The problem considered is the general motion about mean steady flight produced by the action of the rudder.

After references to previous work, the authors select suitable axes and write down a number of formulæ of transformation for angular movements, for forces and moments, and for steady motion, in the usual way.

To assist the computations a graphical chart is prepared of the forces in the form of a diagram of incidence and a function of centrifugal forces about the vertical axis, for constant values of time and yaw, giving two families of curves on the same diagrams.

In a similar manner a family of curves of rolling moment coefficients is plotted as a function of the resolved motions of the wing tip for different constant values of the incidence, about the three axes. The rolling moment is also plotted as a function of the yaw angle. A further diagram gives the yawing moment as a function of the resolved wing tip velocity about the flight axis.

A series of diagrams is drawn exhibiting families of curves corresponding to different incidences plotted on the plane of which the co-ordinates are the resolved 
wing tip velocities about the path axis and the lift axis, each point representing equilibrium of the rolling moments without rudder reaction. Figure is shows lines of equilibrium of forces in the same co-ordinates.

Using the same co-ordinates figure ${ }^{6} 6$ shows the line of equilibrium of moments which is nearly straight cutting the line of equilibrium of forces which has an inflection in three points at which both forces and moments are in equilibrium.

Reverting now to the co-ordinates, inertia forces (of rotation) and incidence, three curves of equilibrium of both rolling moment and forces are exhibited for three different settings of the rudder.

The next figure gives graphically in the same co-ordinates as the last the general graphical representation of the conditions of equilibrium for forces and moments.

With the aid of the relations established the author discusses curved flight and the transition to spiral flight and finally to spin, and the relations on coming out of the spin, all of which are exhibited graphically.

The analysis shows the dependence of symmetrical and unsymmetrical movements of stability for finite movement, which produces such complications that only the numerical study of particular cases is possible.

These show however the nature of the mutual influences of the motion on the different displacements, the derivations of which with respect to time appear as functions of the displacements themselves and of constructional constants.

The possibility of the spin depends on two comparatively simple quantities, the square of the velocity divided by the span and the loading per unit surface multiplied by the difference of the squares of the radii of inertia and divided by the product of span and chord. The most effective method of overcoming a tendency to spin appears to be an alteration of the moments of inertia by a new distribution of masses, but this method has not yet been sufficiently explored.

A further effective method is power of directional control which keeps the side wind within small limits.

Numerical examples show how sensitive the conditions of entering and leaving a spin are to particular numerical values of roll and yaw, and how they may differ for the same values in different phases of the motion.

\section{General Design}

Variable Area Wing Aeroplane. (Automotive Industries, 9/3/29, p. 406.) (5.33/10490 U.S.A.)

An auxiliary wing is placed centrally behind the main wing, forming an extension thereof, in normal flight withdrawn under the main wing. From the test figures supplied the device increases the top speed by about io per cent. and diminishes the landing speed by about 5 per cent.

Recent Measurements of Characteristics of Wings with Parts Cut Away. (H. Muttray, Göttingen, Report of the Kaiser Wilhelm Aerodynamical Institute, Z.F.M., I5th April, I929, Vol. 20, Part 7, pp. I61-169.) (5.33/1049I Germany.)

The Greif Glider, the Avimeta Fighter and the Westland Widgeon III., sporting monoplane, are examples of aeroplanes with a marked cutaway of the wings.

Before describing the new experiments on models lengthy extracts are given from the $3^{\text {rd }}$ issue of the Göttingen reports (Air Ministry Notices and Abstracts No. 7).

The experimental work was carried out in the $2.24 \mathrm{~m}$. diameter channel with a wind speed of $30 \mathrm{~m} / \mathrm{s}$. on wings of $20 \mathrm{~cm}$. chord, IOO cm. span. A systematic series of four cut-aways was made from the leading edge or the trailing edge or both. The polars of the four models are plotted in the same chart. 
The important fact is established that by shaping the central section so as to maintain approximately constant lift distribution along the span, the polar differs very little from the uncut wing, the fixed vortex lines running continuously from tip to tip but becoming crowded at the partially cut-away section.

Where this is not done the distribution of lift falls off at the cut-away, and the polars show signs of diversion of the stream within the flying range.

A second series of measurements was made on thick wings with high maximum iift, the connecting portion across the cut-away having a still higher maximum lift coefficient and with $10^{\circ}$ higher incidence.

An auxiliary wing was fitted to the central section forming a slot in the leading edge, and was tested with and without end shields, in the latter case the polar of the original wing being very nearly attained throughout the whole Rying range.

In the third series of tests the central section was cut out and slid forwards or backwards along the chord. The characteristics were adversely affected to an appreciable degree near the stalling point.

Compressed Air Bralies for Landing Carriages. (T. H. Kollinek, Luftfahrt, $7^{\text {th }}$ March, 1929, p. 7r.) (5.55/10492 Germany.)

A compressed air brake has been developed by the firm of Knorr, who are specialists in brakes for railway trains. The air is furnished by a small piston compressor driven either by the engine direct or by means of a separate propeller. Normally the brakes operating the two halves of the landing gear are accurately balanced but for steering purposes the pilot can lock one or other wheel. The apparatus has been tried on a Junkers machine and reduces the landing run by two-thirds. It was possible to turn the machine on the ground on one wheel.

T'est Flights of Rohrbach "Romar." (Flugsport, 6/2/29, No. 3.). (4.14/10493 Germany.)

The German ministry of aerial transport subjected the Rohrbach " Romar" to seaworthiness tests early in December, 1928. The useful load carried varied between three and eight tons, the total weight of machine and load reaching almost twenty tons. The tests proved generally successful with the exception of partial failure of the right wing float. Had it not been for the water-tight construction of the wings, which is a special feature of the Rohrbach design, the machine would probably have beçome a total wreck, as it was it reached port under its own power and the float was repaired.

\section{Metallurgy}

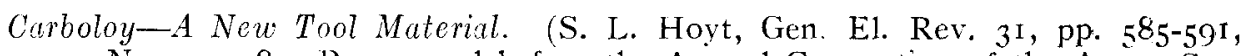
Nov., I928. Paper read before the Annual Convention of the Amer. Soc. for Steel Treating, Philadelphia, Oct., I928.) (ro.6/10494 U.S.A.)

A new alloy of cobalt and tungsten carbide has been produced by the Research Laboratory of the G.E.C. This alloy has a density of approximately I4 and is characterised by extreme hardness. It will scratch natural sapphire and will cut a deep groove in an alundum wheel. The material has been given the name of Carboloy. Applications of Chromium Plating. (W. Blum, Mechanical Engineering, 50,
pp: 927-930, Dec., 1928.) (10.27/10495 U.S.A.)

The chief limitation in the use of chromium for plating is its liability to flake when deformed. Deposition on cutting tools has been successful only in certain cases, and its general application to engine parts which are subjected to strains awaits further improvement in technique. 


\section{Corrosion}

Methods of Testing Resistance of Metals to Corrosion by Weather and Sea Water.

(E. Rackwitz and K. O. Schmidt, Zeitschrift fur Flugtechnik und Motorluftschiffahrt, 28/3/29, No. 6.) (I0. I5/10496 Germany.)

The article is a plea for standardisation of methods for testing corrosion especially of light alloys. The various standard methods employed by the D.V.L. are described in detail. The method specially favoured by the author consists in determining the ultimate tensile and extension of the specimen both in the normal and corroded stage. Provided suitable precautions are observed as to the place in the corroded specimen from which the test piece is cut a satistactory agreement between the progress of corrosion and the change in mechanical properties can be traced.

Corrosion of Aluminium. (J. Calvet, Comptes Rendus, T. 188, No. 11, 22nd April, 1929, pp. г111-1161.) (10.27/10497 France.)

Extra pure aluminium by Hoopes' process, 99.95 per cent. Al., shows far less corrosion than pure aluminium, 99.75 per cent. Al., and ordinary aluminium, 99. 2 per cent. Al., under test with variety of acids.

A Problem in Protective Coatings. (F. N. Speller, Industrial and Engineering

Chemistry, Vol. 2r, No. 5, pp. 500-510.) (ro.27/10498 U.S.A.)

Corrosion is determined and controlled by influences external to the metal, which either form or destroy surface films on the metal.

Protective films form more readily in air than in water or soil.

Where the metal is continuously in contact with soil or water, commercial steel or wrought iron suffers about the same under the same conditions of exposure irrespective of method of manufacture or the amount of foreign material present within wide limits.

When exposed in air, however, copper in amounts over 0.15 per cent. has a marked effect in forming a stable surface coating of oxides which increases the life of the metal at least two or three times. This is the result of tests in service extending over a period of more than ten years. There is no such evidence as yet that other additions give additional life.

For highly corrosive conditions where the first cost of metal is not of prime importance, suitable metals are now available, such as the I 8 per cent. chromium -8 per cent. nickel alloy, but in selecting the most economical alloy for any particular purpose it is jmportant first to study the environment and select a metal that contains the elements that will be most likely to form a stable surface film under conditions of service.

Tests of Methods of Protection Against Corrosion by the Atmosphere and by Sea Water. (E. Rackwitz and K. Schmidt, I27th Report of D.V.L., pp. I 37-I 4I.) (Io.27/10499 Germany.)

An account is given of the installation and methods of test in the materials section of D.V.L. Laboratory, Berlin-Adlershof, illustrated by Io diagrams and photographs. The article is entirely descriptive.

\section{Composite Materials}

Micalex. (A. E. G. Mitt, No. 12, pp. 629-631, Dec., 1928.) (10.59/50500 Germany.)

The A.E.G. have introduced a new moulded insulating material called Micalex. The material can be moulded on to metal. Illustrations are given showing numerous applications. 


\section{MiscellaneOUS}

\section{Instruments}

Automatic Pilot. (Les cahiers techniques du comité français de Propagande Aéronautique. Supplement to Les Ailes, No. 4OI, 21/2/1929.) (7.4/105OI France.)

The automatic stabiliser is built by Messgeräte Boykow G. m. b. H. and controls the rudder, the elevator, and the ailerons. The firm also constructs an artificial horizon, the action of which depends on the frictionless precession if a gyroscope. The stabiliser has been fitted to a Junkers machine and its action favourably commented on by Mr. Köhl, of Atlantic fame.

\section{A New Vibrationless Method of Mounting Delicate Instruments. (R. Muller,} Annalen der Physik, No. 5, 1929, pp. 613-657.) (6.37/10502 Germany.)

A critical review shows that the suspension Julius gives satisfactory results in most cases. The underlying principles of this method are investigated, and improvements carried out. These depend on the following three principles: $(a)$ No attempt is made to weaken the vertical component of the vibration; $(b)$ the period of translatory vibration in a horizontal direction is made very large; (c) a new form of damping is employed, using a liquid of suitable viscosity.

Chronograph, marking 1/10,000 sec. (P. Lejoy, Comptes Rendus, No. 17, T. I88, 22nd April, 1929, pp. 1089-1091.) (6.48/10503 France.)

The pendulum alters a capacity in a circuit with an amplifier. The emitted signal is amplified, and causes the movement of a spot light with a velocity of $120 \mathrm{~cm} . / \mathrm{sec}$.

All the elements of the apparatus are ordinarily available in a laboratory.

Examination of contact pendulums shows a relative fineness of subdivision of $1 / 10,000$ sec. to $1 / 1,000$ sec. in favour of the capacity pendulum.

\section{Wireless}

D./F. Apparatus on Aircraft. (126 D.V.L. Report concld., Zeitschrift fur Hochfrequenztechnik, No. 4, April, 1929, p. I32.) (13.4/10504 Germany.) The new direction finding apparatus designed by Telefunken $\mathrm{Mk} . \quad{ }_{173} \mathrm{~N}$ is fully described. Flight results obtained by this apparatus are given, showing the relation between the angular minimum zone and the distance from the directional station. Using both compass and directional wireless a mean total error of 5 degrees between the true and calculated course was obtained.

Ignition Shielding for Radio Operation. (Lawrence A. Hyland, Aviation, 23/3/29, Vol. XXVI., No. 12, p. 886.) (13.6/10505 U.S.A.)

Practically all the early shielding efforts were conducted on the Liberty engine, which has a notoriously weak ignition systeni. If an additional capacity were introduced in the form of a tight metal shield over the individual wires, too much energy was diverted and the spark in the plug became uncertain. A high tension magneto of modern design has a large power reserve and the added capacity of the wire due to the shielding results in a hotter spark. Radial interference can only be prevented if the sparking plugs themselves are shielded. Prior effects of shielded plugs had lacked the necessary electrical insulating and heat radiating properties essential in modern high compression engines. The Naval Research Laboratory of the U.S.A. have developed a shielded plug which was completely satisfactory in practice. On account of the largely increased radiating surface this plug will offer entirely new possibilities for cooling. It is confidently expected that aircraft receiving performance will shortly be comparable to that obtained on the ground with heavier and bulkier equipment. 
Measurements with Short Wave Tubes. (H. Hornung, Ann. d. Phys., I929, Vol. I., Part 4, pp. 417-456.) (1 2.7/10506 Germany.)

The paper is supplementary to the investigation on short wave lengths (under I metre) carried out by K. Kohl.

Diagrams exhibit the types of valve used and the connections.

The wave length depends principally on the magnitude of the small oscillating circuit of the valve, which is bridged by the grid-anode capacity and their connections. With increasing flow of electrons at constant anode and grid voltage the wave length falls off in linear relation. With increasing grid voltage and constant anode voltage and electron stress the wave length falls off in linear relation. With increasing anode voltage and constant electron stress and grid voltage the wave length increases almost in linear relation. The shortest wave length observed was $30 \mathrm{~cm}$.

\section{Bomb-Sighting}

Investigation of Bomb Trajectories. (Giavanni Bruno, Technical Notices of the Italian Air Ministry, No. ‘', January, I929, page 27.) (9.5/10507 Italy.)

The effect of variation in wind speed angle of inclination, etc., is shown by means of worked out examples.

Recent Development in Aircraft Armament. (Capt. R. C. Coupland, Aviation, 5/1/29, p. 33.) (9.5/10508 U.S.A.)

Improvement in the accuracy of bombing has been brought about by consideration of the following points :-

(I) Stabilisation of the aeroplane proper;

(2) Stability of the bomb sight;

(3) The accuracy of the director equipment;

(4) The mechanical releasing apparatus for the bombs;

(5) Flying characteristic of bomb.

One of the latest types of bomb sights used in the American Army is illustrated (Mark D.4). The airplane is directed on its course by the bomber using a synchronized indicator, or pilot director, operating directly and automatically from the sighting equipment. To correct for wind velocity, angle of approach, speed of target and the speed of bomber, it is a question of referring the angular velocity to a constant speed device. The difference in speed of the two elements controls a sight reference point, which is in turn calibrated in such a manner as to give the proper corrections for the known ballistics of the bomb.

In the D. 4 bomb sight the constant speed device is an escapement mechanism similar to a clock. The velocity of angular travel is obtained by manipulating a hand crank. There is a hand adjustment for altitude and the variations of bomb ballistics due to the types and sizes of bombs concerned. Several developments are under consideration.

\section{Meteorology}

The Transfer of Heat by Radiation and Turbulence. (D. Brunt, Proc. Roy. Soc., A. I 24 , No. $793,2 / 5 / 29$, pp. 201-218.) (6.23/10509.)

In applying the mathematical theory of stability to the atmosphere it has been pointed out in recent years that the thermal conductivity determined by the kinetic theory is negligibly small.

It has, therefore, to be replaced by a symbol representing the effective transference of heat. The author follows up the suggestion, due to Helmboltz, that radiation and absorption are responsible for the transfer of heat on a much larger scale than molecular conductivity and finds a coefficient $K_{R}$ which he calls the 
radiative diffusivity, of an order reaching $1.3 \times \mathbf{1 0}^{3}$. The corresponding coefficient for molecular conduction is about 0.17 in the same units.

Prof. G. I. Taylor has introduced an eddy coefficient $\mathrm{K}$ which can only be determined experimentally from each particular case, and which has been observed with a value as high as $10^{5}$ during the day, but in inversions at night is of the order of $10^{3}$. During unstable day-time conditions $\mathrm{K}$ is of more importance than $K_{R}$. None the less $K_{R}$ must have a large effert in determining the initial type of instability.

Following G. C. Simpson, it is demonstrated that water vapour has a decisive effect in determining $\mathrm{K}_{\mathbf{n}}$.

Temperature measured by thermometer is the most convenient variable in discussing transfer of heat by turbulence and not the so-called potential temperature, which has been used in a number of previous papers on the subject.

Taylor's original discussion (Phil. Trans. I915) was for incompressible fluids. The author extends these results to a compressible fluid.

The paper is an important addition to the comparatively small body of results on the instability of a viscous fluid unequally heated.

\section{Towed Flight}

Toued Flight. (A. Lippisch, Z.F.M., Vol. 20, P. 3, 14/2/29, pp. 71-74.) (15.22/10510 Germany.)

A method is given for reducing the results obtained by towing a glider behind a power-driven aeroplane.

In addition to the usual variables, the direction and tension of the towing line is observed, and the lift and drag are deduced by elementary methods.

The separation of the lift and drag of the two aircraft is carried out and the results are exhibited graphically in 9 diagrams.

\section{Fire Prevention}

Aviation Fire Prevention in the Navy. (Lieutenant Commander C. G. McCord, U.S.N. Member, Superintendent of Tests, Naval Aircraft Factory, Journal of the American Society of Naval Engineers, Vol. XLI., No. 2, May, 1929, p. 239.) (I6.12/1051I U.S.A.)

The apparatus tested by the Navy and War Departments emitted either carbon tetra chloride or carbon dioxide snow and gas. Two types of engines were employed with each type of extinguishing apparatus, one a radial and the other a $V$ type. The engines were literally drenched with petrol, and the fire fanned by a propeller placed in the vicinity. A satisfactory extinguisher of the carbon dioxide type weighed $5^{2.5}$ lbs. complete. 